\title{
RETÓRICA, ARGUMENTAÇÃO E DISCURSO EM RETROSPECTIVA
}

\author{
Maysa de Pádua Teixeira Paulinelli* \\ Pontifícia Universidade Católica de Minas Gerais \\ Belo Horizonte, Minas Gerais, Brasil
}

\begin{abstract}
Resumo: Neste trabalho, propomos a elaboração de uma retrospectiva dos estudos da argumentação de procedência retórica, com vistas à reconstrução crítica dos percursos trilhados desde o mundo clássico, até as pesquisas mais contemporâneas no âmbito da Análise do Discurso. Discorremos inicialmente sobre a retórica clássica e, sem seguida, apresentamos os postulados da Nova Retórica, de Chaïm Perelman, e da argumentação no discurso, de Ruth Amossy. Após identificar e correlacionar os principais aspectos de cada corpo teórico, concluímos que a Nova Retórica é um modelo filosófico cujas categorias apresentam dificuldades práticas de operacionalização, devido a seu alto grau de abstração. Dessa forma, ao articular os postulados filosóficos de Perelman e as contribuições da Análise do Discurso, Amossy promove um notável avanço no campo dos estudos da argumentação, fornecendo ao pesquisador um referencial teórico-metodológico que permite a realização de uma ampla análise linguístico-discursiva de diversos corpora de natureza persuasiva.
\end{abstract}

Palavras-chave: Retórica. Persuasão. Argumentação. Discurso.

\section{INTRODUÇÃO}

Neste trabalho, propõe-se uma revisão dos estudos desenvolvidos em torno da argumentação de procedência retórica, com vistas à reconstrução crítica dos percursos trilhados desde o mundo clássico, até as pesquisas mais contemporâneas no âmbito da Análise do Discurso.

Os estudos sobre argumentação compõem um campo vasto, complexo e multidisciplinar, já que o próprio ato de argumentar encontra espaço em todos os lugares onde exista a abertura para a dúvida e para o conflito, em que não se disponha de uma verdade definitiva a respeito de um dado. Tal abertura faz com que a matéria seja do interesse de diversas áreas do conhecimento humano, como o Direito, a Sociologia, a Filosofia e as Ciências da Linguagem, embora apenas recentemente tenha alcançado o estatuto de objeto legítimo de investigação linguística.

Dada a complexidade e a abrangência desse domínio, selecionamos como objeto de estudo a Nova Retórica, de Perelman, que, ao retornar à tradição clássica e recuperar fundamentos da retórica e da dialética, elabora um trabalho original, denso, de importância inquestionável para juristas, filósofos e linguistas, e o trabalho de Ruth Amossy, cujos esforços têm sido direcionados no sentido de propor uma articulação dos postulados da Nova Retórica aos instrumentos de uma análise linguística de viés

\footnotetext{
* Doutora em Linguística e Língua Portuguesa - PUC-MINAS. Pós-doutoranda na Universidade Federal de Ouro Preto - UFOP. Email: maysapadua@yahoo.com.br.
} 
discursivo, com avanços consideráveis para as pesquisas em argumentação. Com isso, excluímos de nossa apreciação outras teorias que, em maior ou menor grau, se dedicam ao estudo da argumentação, como por exemplo, a Semiolinguística (CHARAUDEAU, 2009) e a Pragmática Sociológica e Filosófica do Agir Comunicacional (HABERMAS, 1990).

Antes de adentrarmos o campo das teorias contemporâneas, é importante apresentar os fundamentos retóricos que serviram de base aos constructos posteriores. Por isso, abordamos também em nosso trabalho as origens retóricas da argumentação.

\section{HISTÓRIA DAS TEORIAS E DEBATES}

Atribui-se a Aristóteles, na Antiguidade clássica, a sistematização dos estudos sobre os meios de persuasão em quatro dimensões argumentativas: a demonstração, a retórica, a sofística e a dialética (MENEZES, 2004). Nesse momento, a retórica gozava de grande prestígio no meio social, pois estava em consonância com o perfil democrático da sociedade ateniense.

Mais adiante, durante a Idade Média, a retórica perde o status adquirido com a sistematização de Aristóteles, o que encontra justificativa na moral cristã em vigor no mundo medieval, que pregava um conceito absoluto de verdade. Para Reboul (2004), contudo, a retórica desenvolveu-se durante todo esse período, na literatura profana e até mesmo na pregação da Igreja.

Mudanças fundamentais ocorrem no interior do programa retórico com o advento da Idade Moderna. Sob o impulso da racionalidade científica, promoveu-se uma cisão entre a dialética, cujo raciocínio foi plenamente identificado com o cientificismo em voga, e a retórica, agora esvaziada da concepção de discurso com vistas a persuadir, para reduzir-se ao estudo dos meios de expressão ornados e agradáveis da Poética (REBOUL, 2004).

No século XVII, Descartes lança a concepção de dúvida metódica, segundo a qual se considera falso tudo o que não é verdadeiro, incluído aí o verossímil, de onde parte o raciocínio retórico. Posteriormente, o positivismo, seguindo a esteira de Descartes, condenou a retórica em nome da verdade científica, enquanto o romantismo a rejeitou em nome da sinceridade. Nesse mundo dominado pelo racionalismo, não havia lugar para uma forma de raciocínio assentada no provável, em prejuízo do certo e do verdadeiro. Em vez de ocupar-se com a retórica e com opiniões enganadoras, acreditava-se que seria mais proveitoso para o homem buscar o conhecimento da verdade, com amparo na filosofia de cunho racional (MENEZES, 2004).

A partir daí, a retórica viveu um período de esquecimento quase completo, para ser novamente recuperada somente a partir do final dos anos de 1950, juntamente com o desenvolvimento dos meios de comunicação de massa e a consolidação dos Estados democráticos. Essa retomada se deve, sobretudo, a Perelman que, em 1958, publica, juntamente com Olbrechts-Tyteca, uma compilação dos estudos que vinha desenvolvendo acerca das técnicas discursivas empregadas a fim de se promover, ou reforçar, a adesão dos espíritos às teses que lhes são apresentadas. Esses estudos, 
elaborados no âmbito da Escola de Bruxelas, representaram uma tentativa de recuperação dos postulados da retórica e da dialética para a análise argumentativa, ao mesmo tempo em que se constituíram como forma de oposição à concepção cartesiana de razão e de raciocínio (PLANTIN, 2002).

Apesar da grandiosidade da obra de Perelman, Amossy (2002) explicita que seu lançamento teve impacto reduzido e influência muito limitada no cenário linguístico dos anos de 1960 e 1970. Plantin (2002) esclarece que a ênfase conferida pelo autor ao gênero judiciário e ao discurso filosófico fez com que sua pesquisa agradasse especialmente aos círculos especializados de filósofos do Direito, e que fícasse circunscrita a esse meio.

Ademais, as Ciências da Linguagem ainda sentiam a influência do estruturalismo de Saussure. Ao privilegiar o estudo da língua como um sistema, essa perspectiva implicava que o uso fosse excluído do campo da investigação científica. Amossy (2005) relata que, na medida em que a utilização da linguagem em contexto não podia ser objeto de uma pesquisa legítima, a dimensão retórica escapava necessariamente ao trabalho dos linguistas.

Paralelamente ao programa de Perelman, a argumentação de procedência retórica retorna à cena de forma indireta, através dos estudos da filosofia analítica anglosaxônica, quando então se consolida uma tendência de se estudar não somente o sistema da língua, mas também o enunciado em contexto. Austin (1970) lança a noção de ato ilocucional, em que uma ação é atrelada a uma palavra, e de ato perlocucional, que consiste em produzir um efeito sobre aquele a quem se dirige. Essa concepção de linguagem como ato dotado de uma força permite a retomada de uma tradição retórica secular cujo interesse estava perdido (PLANTIN, 2002). Em torno dessa concepção de Austin de que o dizer implica um fazer, desenvolveu-se a Pragmática, a qual designa menos uma disciplina precisa que um modo de apreensão da linguagem.

É interessante observar que, segundo Plantin (2002), a Análise do Discurso manteve-se inicialmente distante dessa revitalização nos estudos da argumentação, pois estava voltada para questões políticas e ideológicas, na esteira de trabalhos propostos por pensadores como Althusser, Deleuze, Foucault, Lacan e Pêcheux. Plantin (2002) esclarece ainda que a Análise do Discurso praticada entre os anos de 1960 e 1970 instala a política na teoria do discurso, considerando que as noções de sujeito, de sentido, de escolha e de intenção, fundamentais para a retórica aristotélica assim como para a Nova Retórica de Perelman, eram consideradas excessivamente tradicionais, conservadoras e reacionárias, por derivarem de uma visão de mundo clássica.

Partindo das considerações filosóficas a respeito da argumentação e aliando-as aos elementos próprios das Ciências da Linguagem, as teorias da argumentação propostas desde então desenvolveram seus fundamentos e implicações, cada qual elegendo pontos de interesse específicos e trabalhando com orientações diferentes, apropriando-se do conhecimento legado pelos clássicos e criando ramificações que podem, em graus diferentes, contribuir para o entendimento da argumentação no seu sentido mais amplo. Nesse sentido, podem ser citadas a Teoria da Argumentação na Língua, de Oswald Ducrot (DUCROT, 1989), a Pragma-Retórica, de Marcelo Dascal (DASCAL, 2006), a 
Pragma-Dialética, de van Eemeren e o grupo de Amsterdã (van EEMEREN; HOUTLOSSER, 2004), entre outras.

Destacamos, entre essas teorias, a pesquisa de Ruth Amossy, considerada a sucessora de Perelman na recuperação dos estudos retóricos, ao propor uma teoria de análise da argumentação em uma vertente discursiva, partindo de clássicas considerações filosóficas e aliando-as aos elementos próprios das Ciências da Linguagem.

$\mathrm{Na}$ sequência, apresentamos uma síntese programática sobre a Retórica, que foi o modelo filosófico fundador das teorias de argumentação selecionadas como objeto de nosso trabalho.

\section{RETORNO ÀS ORIGENS: A ARTE RETÓRICA}

O nascimento da retórica é tradicionalmente atribuído ao siciliano Córax e remonta ao século V a.C., a um período histórico caracterizado pela transição de um governo tirânico para um regime democrático. Nesse período, inúmeros conflitos judiciários foram travados por cidadãos que, despojados de seus bens pela tirania, recorriam à justiça na tentativa de reavê-los. Contudo, não se conhecia a figura do profissional da advocacia como se conhece nos dias atuais, de forma que os cidadãos que buscassem a solução de seus conflitos no judiciário deveriam providenciar por si mesmos a sustentação de suas teses (REBOUL, 2004).

Atentos a essa crescente necessidade prática de elaboração discursiva, Córax e seu discípulo Tísias, por volta de 465 a.C., lançaram o primeiro tratado metódico sobre a arte da palavra - um manual que apresentava, de forma didática, lições de como bem sustentar uma tese em juízo, com vistas a vencer qualquer demanda (REBOUL, 2004).

Nesse momento, a retórica, entendida como a arte de persuadir, adquiria cada vez mais prestígio, pois existia a crença de que aquele que dominasse suas técnicas seria capaz de convencer qualquer pessoa de qualquer coisa. Portanto, naquele contexto judiciário, a praxis indicava que a causa vencedora em um conflito judicial não tinha que ser necessariamente a mais justa, mas com certeza, a mais eficientemente sustentada em juízo, o que permite a observação de que a retórica não argumenta a partir do verdadeiro, mas do verossímil (REBOUL, 2004).

Da Sicília, então dominada pelos gregos, a retórica migrou para Atenas e lá encontrou terreno fértil para o desenvolvimento de seus postulados, com o florescimento da polis grega, onde as decisões políticas eram tomadas mediante ampla participação popular, em debates coletivos organizados para que as pessoas pudessem exercer seu direito de livre opinião e expressão, no interior de um quadro institucional dotado de leis (AMOSSY, 2002).

Considerando esse contexto em que nasceu e se desenvolveu a retórica, torna-se plenamente compreensível o realce que os pesquisadores dão a seu caráter sociocultural de instrumento de exercício da cidadania que, segundo Amossy (2006), permitia tanto a boa marcha da justiça, pelo manuseio da controvérsia, como o bom funcionamento da democracia, pela prática da palavra pública. 
Paralelamente à retórica, desenvolveu-se também na Antiguidade clássica o programa conhecido como sofística. Nesse domínio, a persuasão do outro pela linguagem é um alvo a ser alcançado a qualquer custo. Percebe-se, assim, uma semelhança entre retórica e sofística no que diz respeito aos objetivos pretendidos, que é a persuasão, mas o repertório de estratégias permitidas por esta última é bem mais amplo. Ambas têm em comum a utilização de técnicas discursivas para persuadir, mas o campo de atuação da sofística para a consecução desses fins é bem mais maleável e muitas vezes dispensa um compromisso com a verossimilhança (REBOUL, 2004). A busca da vitória a qualquer custo, desvinculada de um ideal de verdade, rendeu inúmeras críticas aos sofistas, mas, segundo Reboul (2004), não se pode deixar de reconhecer as contribuições filosóficas que essa forma de pensar legou paras os modelos de análise argumentativa desenvolvidos posteriormente, notadamente no aspecto de que a verdade é um acordo entre interlocutores: acordo final, que resulta da discussão e, ao mesmo tempo, acordo inicial, sem o qual a discussão não seria possível.

Reboul (2004) aponta também pontos de contato entre a retórica e a dialética. $\mathrm{Na}$ filosofia aristotélica, segundo Reboul (2004), uma e outra estariam em um mesmo plano, uma não se submetendo à outra. Ambas são capazes tanto de provar uma tese quanto o seu contrário; ambas são universais, no sentido de não serem ciências, mas técnicas que buscam identificar o que cada caso tem de persuasivo; ao contrário da sofística, as duas são capazes de fazer a distinção entre o verdadeiro e o aparente; por fim, tanto uma quanto a outra utilizam dois tipos idênticos de raciocínio argumentativo, que são a indução e a dedução. As afinidades entre as duas técnicas são tantas e tão decisivas que quase nos fazem crer que se trata de uma só disciplina. Contudo, Reboul esclarece que a retórica pode ser uma aplicação da dialética:

Retórica e dialética são, pois, duas disciplinas diferentes, mas que se cruzam como dois círculos em intersecção. A dialética é apenas um jogo intelectual que, entre suas possíveis aplicações, comporta a retórica. Esta é a técnica do discurso persuasivo que, entre outros meios de convencer, utiliza a dialética como instrumento intelectual. (REBOUL, 2004, p. $39)$.

Parece-nos relevante tecer ainda algumas considerações a respeito de duas questões pontuais dignas de atenção especial: a primeira delas diz respeito à dimensão linguageira da retórica aristotélica e a segunda, às relações entre auditório e gêneros oratórios.

Em primeiro lugar, como afirma Reboul (2004), a Retórica concebe a argumentação como o ato de destinar a palavra a um auditório, submetendo a ele teses não necessariamente verdadeiras, mas verossímeis e razoáveis. Segundo Amossy (2006), essa característica da retórica se justifica porque interessa a ela o que faz parte do humano, e o que resulta do homem é quase sempre da ordem do verossímil, do opinável, do plausível. Nesse território, em que a verdade absoluta não pode ser garantida, a retórica encontra seu lugar, permitindo ao homem desenvolver raciocínios e comunicar-se com segurança relativa, garantida por normas mínimas de racionalidade. Por isso, ela é exercitada em todos os domínios onde se delibera com liberdade para se 
chegar a uma decisão, não com fundamento em uma verdade absoluta, mas com base no que é razoável.

Amossy (2006) afirma que, da própria delimitação do objeto da retórica clássica, sobreleva sua dimensão linguageira: trata-se de um discurso que só tem razão de existir no interior de um processo de interação, onde um locutor se amolda à imagem do alocutário, a fim de agir sobre o seu pensamento. Portanto, Aristóteles já postulava o dizer como fazer, muito antes do advento da Pragmática (AMOSSY, 2006).

Trata-se, ainda, de uma atividade verbal que mobiliza técnicas e estratégias para atingir seus fins de persuasão, por acreditar na capacidade de raciocínio - logos - do auditório. Entretanto, não se pode perder de vista que o logos não é, para Aristóteles (1998), mais que um dos polos da empresa de persuasão retórica: o logos (apelo à razão por meio dos argumentos), juntamente com o pathos (procedimentos que visam a suscitar as paixões do auditório) e o ethos (caráter moral que o orador deve apresentar no próprio discurso), compõe uma tríade probatória fundamental (MENEZES, 2004).

Lembramos que, para Aristóteles, "as provas de persuasão fornecidas pelo discurso são de três espécies: umas residem no caráter moral do orador; outras no modo como se dispõe o ouvinte; e outras, no próprio discurso, pelo que este demonstra ou parece demonstrar." (ARISTÓTELES, Ret. I, 1348b).

A posição ocupada pelo conceito de auditório na retórica clássica também é um ponto a ser sublinhado. Aristóteles (1998) classifica os discursos em três grandes gêneros oratórios, a saber, o deliberativo, o judiciário e o epidítico, de acordo com as funções que os auditores têm de desempenhar em cada um deles: deliberar, julgar ou simplesmente usufruir, como espectador, do desenvolvimento oratório.

Estabelecidas as bases sobre as quais se desenvolveu o estudo da argumentação na Antiguidade clássica, partimos agora para a exposição do legatário mais ilustre, contemporaneamente, de toda essa tradição filosófica: Chaïm Perelman.

\section{A NOVA RETÓRICA: UMA LÓGICA DOS JUÍZOS DE VALOR}

Chaïm Perelman atribui a sua teoria da argumentação a denominação Nova Retórica. Além de homenagear a tradição clássica em que foi inspirada, a designação mostra a preocupação do autor em deixar clara a aproximação existente entre sua nova teoria e a retórica aristotélica, onde buscou matéria-prima para a criação de seus postulados. Por outro lado, poderíamos questionar por que Perelman não intitulou seu trabalho de Nova Dialética, já que boa parte do conteúdo da Nova Retórica concerne às provas que Aristóteles chama de dialéticas e, por esse motivo, aparentemente, haveria uma maior proximidade entre o novo modelo e a dialética. O uso de 'dialética', contudo, poderia acarretar confusões, devido aos vários significados que foram adicionados a esse termo no decorrer do tempo. O mesmo não se dá com a palavra 'retórica', que, como já se discutiu, caiu em desuso por longo período (MOSCA, 2001).

Entretanto, o principal motivo da aproximação entre a teoria da argumentação de procedência perelmaniana e a retórica aristotélica é a ênfase no fato de que é em função de um auditório que qualquer argumentação se desenvolve, pois a ideia de adesão e de 
espíritos aos quais se dirige um discurso, tão importante para a abordagem de Perelman, é também preocupação central na retórica antiga. Para Amossy (2002), se Perelman prefere denominar seu trabalho retórica em vez de dialética, não é senão em virtude da relação constitutiva da palavra ao auditório.

Apesar da menção explícita à retórica, é errôneo pensar que sua obra limita-se a uma releitura dos clássicos gregos e latinos. $\mathrm{Na}$ verdade, ao se apropriar dos elementos oriundos desses modelos, Perelman, como resultado de suas pesquisas, constrói um domínio original, coerente com as peculiaridades de seu tempo e conectado às inovações que as Ciências da Linguagem apresentavam no mesmo período em que desenvolvia suas pesquisas.

Em alguns aspectos, seu trabalho chega a ultrapassar os limites dessa retórica antiga. Em outros, restringe-o, na medida em que não desenvolve alguns pontos, como, por exemplo, o aspecto da eloquência, já que o foco na compreensão do mecanismo do pensamento justifica uma maior preocupação com as técnicas de raciocínio do que com a maneira pela qual se efetua a apresentação pública do discurso, no que se refere aos seus elementos não verbais. $\mathrm{O}$ interesse pelas técnicas argumentativas, contudo, justifica-se em função do resultado obtido por meio delas. O objeto de análise da teoria da argumentação perelmaniana, portanto, é composto pelos recursos discursivos para se obter a adesão das mentes, com ênfase na técnica que utiliza a linguagem para persuadir e convencer (PERELMAN; OLBRECHTS-TYTECA, 1996).

Uma das preocupações centrais de Perelman (1987) é a de evidenciar que existem outras formas possíveis e igualmente válidas de pensamento que não só o raciocínio lógico. A crença na superioridade da lógica foi um dos fatores responsáveis pelo esquecimento quase completo da retórica por longos períodos, o que para Perelman era inaceitável. Por isso, em sua obra, parte da concepção de que, entre a demonstração científica e a demonstração arbitrária das crenças, há uma lógica do verossímil, representada pela argumentação. Assim como Aristóteles (1998), Perelman (1987) entende que o campo da argumentação é o campo do verossímil, do plausível, do provável.

A fim de ressaltar as características particulares da argumentação e os problemas inerentes a seu estudo, Perelman apresenta uma distinção inicial entre demonstração e argumentação, de onde resultam consequências sociológicas fundamentais para o pensamento que irá desenvolver ao longo de toda a sua obra:

\footnotetext{
A argumentação é essencialmente comunicação, diálogo, discussão. Enquanto a demonstração é independente de qualquer sujeito, até mesmo do orador, uma vez que um cálculo pode ser efetuado por uma máquina, a argumentação por sua vez necessita que se estabeleça um contacto entre o orador que deseja convencer e o auditório disposto a escutar. (PERELMAN, 1987, p. 235).
}

Observa-se que a atenção para a forma como os argumentos são recebidos pelos alocutários desloca o olhar do pesquisador do eixo da produção para o eixo da recepção do discurso, pois é necessário que o orador desenvolva sua argumentação na medida adequada para atingir um determinado auditório, o qual apresenta características muito próprias e diferenciadoras, resultantes do tempo e do espaço nos quais ele se constitui. 
Ainda no âmbito da dimensão sociológica da argumentação, encontramos em Perelman e Olbrechts-Tyteca (1996) a reflexão sobre os requisitos necessários para a instalação de um debate. Assim, para que uma argumentação se desenvolva, é necessário o preenchimento de determinadas condições prévias. Uma delas, e considerada de fundamental importância, é a formação de uma "comunidade intelectual" interessada na discussão de determinado assunto. Em outras palavras, é preciso que exista um interesse mútuo na abordagem de uma polêmica; que o sujeito argumentante tenha autoridade ou legitimidade para assumir o posto de orador e que aqueles a quem se dirige estejam dispostos a formar uma opinião - ou modificar a que já têm - sobre determinado assunto. Se a questão é tida como "fora de discussão" para uma das partes, não há como se instalar a argumentação.

Podemos extrair desse ponto uma informação fundamental sobre uma característica da argumentação, também presente na retórica clássica, que é a existência inicial de teses conflituosas a serem discutidas. Definindo a argumentação na "contradição discursiva", temos que, além de linguageira, situada, afetiva, figurativa e metafórica, ela é também problematizante (PLANTIN, 2002).

A sociedade, através de suas instituições, estabelece regras para a convivência entre os indivíduos, que regulamentam, inclusive, as formas pelas quais uma conversa pode ser iniciada. A título de ilustração, Perelman (1987) fala "nas instituições judiciárias e políticas, na organização das Escolas e das Igrejas, nas festas nacionais ou religiosas que, periodicamente, permitem evocar determinados assuntos diante de certos auditórios." (PERELMAN, 1987, p. 236).

Em algumas instâncias, o exercício da argumentação é monopólio de pessoas ou de organismos especialmente habilitados para isso, de modo que, para poder tomar a palavra, é mister possuir uma qualidade, ser membro ou representante de um grupo. Perante certos auditórios, os problemas de habilitação são minuciosamente regulamentados. Em um processo judicial, por exemplo, para exercer a prerrogativa da palavra nos autos, é necessário que o locutor seja um advogado, um Promotor, ou ainda, que esteja investido do poder institucional de julgar, como o Juiz de Direito.

O exercício eficaz da argumentação pressupõe ainda uma linguagem comum, sem a qual a interlocução é impossível. Ao contrário da demonstração, em que normalmente se emprega uma língua artificial, como a álgebra ou a química, por exemplo, a argumentação desenrola-se sempre em língua natural.

Considerar a argumentação em seu âmbito sociológico implica, como já se afirmou, reconhecer que nesse terreno os raciocínios são desenvolvidos por um locutor em função de um alocutário, nomeados respectivamente, por Perelman (1987), de orador e auditório, a exemplo da denominação que essas duas instâncias receberam na retórica clássica.

Aliás, um elemento central da Nova Retórica é a concepção de que toda argumentação se desenvolve em função do auditório, ao qual ela se dirige e ao qual o orador deve se adaptar. O auditório, em Perelman, é sempre uma construção do orador e essa construção se dá por meio de um jogo de imagens. Ainda assim, é preciso que essa construção idealizada seja o mais próxima possível da realidade, pois uma imagem inadequada do auditório, resultante de erro, de ignorância ou de um discurso imprevisto 
de circunstâncias, pode ter as mais desagradáveis consequências para o projeto de persuasão (AMOSSY, 2006).

Perelman verifica que há uma relação estreita entre a qualidade do auditório e a qualidade da argumentação, ao contrário do que defende Aristóteles (1998), para quem quanto mais científico for um discurso, mais distante ele está da retórica:

\begin{abstract}
Para ele [Aristóteles], quanto mais um discurso é científico, mais é demonstrativo e mais se afasta da retórica, salvo quando se trata de discutir os princípios de cada disciplina [...] Mas, segundo o nosso ponto de vista, existe argumentação desde que o discurso não seja redutível a um cálculo. Então, no caso de um meio especializado, quer se trate de cientistas, de juristas, de adeptos de uma ideologia ou de uma religião, é indispensável conhecer o conjunto das crenças, das aspirações e das regras sobre o qual existe um acordo e em relação ao qual todo o recém-chegado tem de ser iniciado. (PERELMAN, 1987, p. 237).
\end{abstract}

Os alocutários visados em um discurso argumentativo podem variar quanto ao sexo, à idade, à instrução, ao temperamento, enfim, podem estar sujeitos a divergências de ordem política, econômica, social, etc. Verifica-se, assim, a existência de uma tipologia de auditórios, compostos por membros que não compartilham necessariamente dos mesmos modos de ver e de dizer. Nesses casos, o orador deve renovar habilmente seu repertório de argumentos, apelando também a valores, crenças e ideais distintos, de forma a alcançar o maior número possível de mentes. Segundo Amossy (2002), a empresa da persuasão se mostra especialmente perigosa, e também mais interessante, quando o auditório possui membros cujos pontos de vista são diferentes.

O conceito de auditório comporta também variações de ordem quantitativa, partindo do próprio orador, que se divide em dois na deliberação íntima, até o conjunto dos seres capazes de razão, quando então é denominado auditório universal. Este parece ser, no campo da teoria da argumentação de procedência perelmaniana, o mais nobre dos auditórios a serem conquistados. Para alcançar sua adesão, é preciso manejar argumentos os mais próximos possíveis da verdade e da lógica. Parece-nos que se trata, na verdade, de um ideal argumentativo, que não existe na realidade: "aqueles que se dirigem ao auditório universal não podem supor como admitidos senão fatos objetivos, verdades incontestáveis, valores universais, supostamente admitidos por todos os seres razoáveis e competentes." (PERELMAN, 1987, p. 240).

A relação entre orador e auditório fundamenta-se na instauração de um acordo prévio, que é o ponto de partida de toda argumentação. Havendo uma comunidade de espíritos interessada no debate de determinada questão, a instalação de um acordo entre o orador e o auditório é o primeiro passo para que se possa ter a argumentação, pois o enunciador só pode desenvolver seu projeto de persuasão conectando seus argumentos a teses já admitidas pelos ouvintes, sob pena de ser sumariamente rejeitado.

Esse acordo tem por objeto ora o conteúdo das premissas explícitas, ora as ligações particulares utilizadas, ora a forma de servir-se dessas ligações. Por outro lado, a própria escolha das premissas e sua formulação, com os arranjos que comportam, estão impregnadas de valor argumentativo e se configuram como uma preparação para o raciocínio que, mais do que uma introdução dos elementos, já constitui um primeiro passo para a sua utilização persuasiva (PERELMAN, 1987). 
Escolher as estratégias mais adequadas é fundamental porque a adesão é suscetível de maior ou menor intensidade, uma vez que o assentimento tem seus graus e uma tese, quando admitida, pode não prevalecer diante de outras, se a intensidade da adesão for insuficiente. Assim, mesmo concedida a adesão inicial, esta poderá ser negada mais adiante, pois a qualquer momento o auditório pode discordar do que o orador lhe apresenta. Pode também desconfiar do conteúdo das premissas ou ainda se mostrar insatisfeito com o caráter tendencioso de apresentação dessas premissas.

As premissas sustentadas pelo orador e previamente admitidas pelos auditores poderão ser do senso comum ou, ainda, próprias aos integrantes de uma determinada disciplina (científica, jurídica, filosófica ou teológica), e terão estatuto epistemológico variável: ora se tratará de afirmações elaboradas no seio de uma disciplina científica, ora de dogmas, ora de crenças do senso comum, ora de preceitos ou de regras de conduta aprovados, ora, pura e simplesmente, de proposições que foram admitidas pelos interlocutores num estágio anterior da discussão (PERELMAN; OLBRETCHSTYTECA, 1996).

Perelman (1987) lembra que determinados auditórios possuem objetos de acordo próprios, que podem ter natureza ideológica ou profissional. Assim, supõe-se que o homem de fé admite os dogmas da religião que professa, enquanto o Juiz de Direito aceita as normas de direito que deve aplicar aos casos que lhe são submetidos.

Entre os objetos dos acordos de crença ou de adesão que podem servir de premissas - intitulados objetos de acordo - há duas categorias: a do real, que comportaria os fatos, as verdades e as presunções, e a do preferível, incluídos aí os valores, as hierarquias e os lugares.

A concepção de real varia conforme as opiniões filosóficas aceitas, mas, na argumentação, o real se caracteriza por uma pretensão de validade para o auditório universal. É que, nesse território, o objetivo e o universalmente válido não se definem como em uma ontologia ou em uma epistemologia, por meio de critérios intrínsecos. Aqui, o objetivo e o universalmente válido “[...] estão ligados a reações do auditório universal ou, pelo mesmo, àquilo que o orador presume destas reacções." (PERELMAN, 1987, p. 240).

Argumentos baseados em fatos, verdades e presunções postulam, na medida do que é possível em um domínio como a argumentação, um estatuto de proximidade com a realidade objetiva. Por isso, dispensariam, a princípio, o orador de produzir provas para intensificar a adesão quanto a eles.

Em oposição aos argumentos que versam sobre o real (fatos, verdades e presunções), podem ser capitulados aqueles que se fundam no que é preferível: os valores, hierarquias e lugares, que nos determinam as escolhas não em consonância com uma realidade preexistente, mas conforme um ponto de vista determinado, que só podemos identificar com o de um auditório particular, por mais amplo que seja.

$\mathrm{Na}$ argumentação, os valores funcionam como os mais importantes objetos de acordo entre o orador e o auditório na formulação das premissas, pois aqueles que partilham um conjunto de valores comuns se colocam mais receptivos às teses defendidas pelo orador. Estar de acordo com um valor é, segundo Perelman e Olbrechts- 
Tyteca (1996), admitir que um ser ou um ideal deva exercer uma influência determinada sobre a ação e as disposições à ação, sem considerar, contudo, que esse ponto de vista se aplica a todos, uma vez que não há como se impor juízos que dependem da valoração de cada sujeito.

Por serem relativos, instáveis e controversos, os juízos de valor e as hierarquias foram condenados pelos positivistas, que pretendiam que os raciocínios fossem isentos desses elementos de incerteza. Nos campos jurídico, político e filosófico, contudo, fica claro que os oradores recorrem a esses elementos durante todo o discurso argumentativo, a fim de motivar o interlocutor a fazer certas escolhas em prejuízo de outras. Para Reboul (2004), nos domínios da argumentação, é impossível renunciar a esses juízos, pois noções fundamentais de inocente ou culpado, belo ou feio, útil ou nocivo e outras, são sempre formuladas em termos de valor.

A adesão em torno de valores se dá com intensidade variável de indivíduo para indivíduo e de grupo para grupo. Depreende-se, então, que os valores se sujeitam a uma hierarquia, que garante uma ordenação de tudo o que está submetido ao princípio que a rege: "enquanto os valores indicam uma atitude favorável ou desfavorável a respeito daquilo que é assim qualificado, as hierarquias indicam expressamente os valores hierarquizados" (PERELMAN, 1987, p. 242).

Para fundamentar valores ou hierarquias, ou reforçar a intensidade da adesão que eles suscitam, é possível relacioná-los a outros valores ou hierarquias, mas pode-se também recorrer a premissas gerais, chamadas lugares. Há os lugares comuns (gerais), que são afirmações muito amplas acerca do que se supõe valer mais em qualquer domínio, e os lugares específicos, que determinam o que vale mais em um domínio particular.

Para alcançar a adesão de um auditório às suas teses, o orador deve estar munido de um repertório eficaz de técnicas argumentativas, a partir das quais desenvolverá seu raciocínio e conduzirá o raciocínio dos auditores. Essas técnicas se apresentam sob dois aspectos diferentes: ora assumem a forma positiva de processos de ligação, ora a forma negativa de processos de dissociação. A forma positiva consiste na criação de um vínculo de solidariedade entre teses que se procuram promover e as teses já admitidas, enquanto o aspecto negativo busca romper a solidariedade existente entre as teses já admitidas e as que se opõem às teses do orador (PERELMAN, 1987).

Entre os processos de ligação, encontram-se três grandes grupos, que são os argumentos quase-lógicos, os argumentos fundados sobre a estrutura do real e os argumentos que fundam a estrutura do real.

Os argumentos quase-lógicos constroem-se à imagem de princípios lógicos. Por sua estrutura, assemelham-se aos raciocínios formais e mostram uma preocupação do orador em construir um pensamento preciso e bem elaborado. Contudo, por desenvolverem-se em língua natural e por estarem sob o influxo da controvérsia, são passíveis de interpretações distintas, o que os afasta de seu ideal de formalização.

Os argumentos fundados sobre a estrutura do real, por sua vez, são construídos não a partir do que é o real, no sentido ontológico, mas a partir do que o auditório acredita, isto é, daquilo que ele toma por fatos, verdades ou presunções. Já os 
argumentos que fundam a estrutura do real operam por indução, estabelecendo generalizações e regularidades, propondo modelos, exemplos e ilustrações a partir de casos particulares.

O quadro 1 relaciona esses três tipos de argumentos aos seus subtipos:

\section{Quadro 1 - Tipologia de argumentos}

\begin{tabular}{|l|l|}
\hline \multicolumn{2}{|c|}{ Processos de Ligação } \\
\hline Tipos de argumentos & Subtipos de argumentos \\
\hline $\begin{array}{l}\text { Argumentos quase-lógicos } \\
\text { (construídos à imagem de princípios lógicos) }\end{array}$ & $\begin{array}{l}\text { Contradição, incompatibilidade, ironia, ridículo, } \\
\text { identidade, definição, regra de justiça, quase } \\
\text { matemáticos (transitividade, divisão, dilema, } a d \\
\text { ignorantiam) }\end{array}$ \\
\hline $\begin{array}{l}\text { Argumentos fundados sobre a estrutura do real } \\
\text { (no sentido do que o auditório acredita ser o real) }\end{array}$ & $\begin{array}{l}\text { Sucessão, argumento pragmático, finalidade } \\
\text { (desperdício, direção, superação), coexistência } \\
\text { (essência, pessoa - autoridade, argumento } a d \\
\text { hominem), duplas hierarquias, argumentos } a \\
\text { fortiori (“com maior razão") }\end{array}$ \\
\hline $\begin{array}{l}\text { Argumentos que fundam a estrutura do real } \\
\text { (operam por indução) }\end{array}$ & $\begin{array}{l}\text { Exemplo, ilustração, modelo, comparação, } \\
\text { argumento pelo sacrifício, analogia, metáfora }\end{array}$ \\
\hline
\end{tabular}

Fonte: Perelman e Olbrechts-Tyteca (1996).

A dissociação das noções, em oposição às técnicas de ligação, consiste em recusar-se o estabelecimento de uma associação aceita como válida em um momento anterior do debate argumentativo. Busca-se separar as noções em pares hierarquizados, como aparência/realidade, meio/fim, letra/espírito, saber/ignorância, belo/feio, verdade/mentira, virtude/vício. Com isso, a dissociação modifica profundamente as realidades que desliga, dirimindo incompatibilidades e adquirindo o caráter de convincente e duradoura (PERELMAN; OLBRECHTS-TYTECA, 1996).

Para a eficácia da argumentação, é essencial, portanto, que o orador conheça este conjunto de técnicas de associação e dissociação, pois, ao contrário do lógico ou do matemático, que agem no interior de um sistema de elementos fechados, o orador retira seus argumentos de um celeiro indeterminado, composto por teses do senso comum ou de uma disciplina especializada, que podem produzir maior ou menor intensidade de adesão. Tais técnicas, fundadas em procedimentos indutivos e dedutivos, encontram sua razão de ser no jogo interlocutivo e se desenvolvem em função das finalidades persuasivas da argumentação.

Perelman sempre foi alvo de críticas por conferir à sua teoria da argumentação um caráter excessivamente lógico, racionalizante e, também, por não desenvolver um estudo sistematizado sobre o papel das emoções (pathos) e do caráter do orador (ethos) na empresa de persuasão. Examinando o Tratado da argumentação (1996), constatamos que, no bojo das três partes que compõem a obra (Os Âmbitos da Argumentação, O Ponto de Partida da Argumentação e As Técnicas Argumentativas), há apenas referências esparsas ao ethos e ao pathos. De fato, o foco de Perelman encontra-se bastante voltado para o estudo do logos. 
Outro elemento que parece gerar certa rejeição por sua obra nos meios linguísticos é o fato de que Perelman é um jurista-filósofo e, como tal, traz para seus estudos influências do campo da Filosofia e do Direito. Até mesmo os exemplos apresentados por ele ao longo de seus escritos são retirados de corpora não tão usualmente pesquisados na Linguística: o Tratado da argumentação é pleno de citações de filósofos e de juristas. Tudo isso provoca um estranhamento, ou uma "não identificação", dos linguistas para com Perelman.

Diante desse conflito aparente de posições entre um domínio e outro, vemos, na atualidade, um esforço de vários estudiosos das Ciências da Linguagem para desmistificar a obra perelmaniana, movimento que tem a sua frente Ruth Amossy, que busca aliar a dimensão filosófica da argumentação, especialmente em sua vertente retórica (Aristóteles) e neorretórica (Perelman), a uma dimensão linguístico-discursiva, com vistas à criação de um método de análise argumentativa. Em seguida, tecemos algumas considerações acerca das pesquisas de Ruth Amossy.

\section{A ARGUMENTAÇÃO NO DISCURSO}

Em suas pesquisas, Amossy tem buscado uma redefinição da retórica perelmaniana como um dos ramos da Linguística do Discurso, ao fornecer-lhe instrumental teórico-metodológico adequado ao estudo concreto do discurso argumentativo, como se verá adiante.

Inicialmente, Amossy (2005) ocupa-se em solucionar uma questão de delimitação dos campos de interesse da retórica e da Análise do Discurso. A retórica, nesse sentido, se interessa apenas por discursos com propósito persuasivo declarado, enquanto a Análise do Discurso abriga estudos de corpora de natureza mais diversa, a fim de apanhar a articulação entre uma organização textual e um dispositivo de enunciação tributário de determinada situação social. Existiria também uma divergência quanto aos objetos de estudo de uma e outra área: enquanto a retórica focaliza as técnicas argumentativas, a Análise do Discurso estuda todo discurso no quadro de troca onde ele se desenvolve.

Amossy (2005) defende, então, que o pesquisador deve estar atento ao que ela chama de visée argumentativa e dimensão argumentativa: se considerarmos a interação verbal como um jogo de influências recíprocas, podemos entender que todo discurso tende a agir sobre o parceiro, incitando-o a ver e pensar de um certo modo, a partilhar um ponto de vista. Mas nem todos os discursos possuem um mesmo objetivo. Um discurso eleitoral ou publicitário, um manifesto, uma carta aberta se constroem em torno de uma "visée persuasiva", da qual o auditório é bem consciente, ao passo que textos literários não buscam diretamente a persuasão, embora indiretamente comportem também uma orientação argumentativa, na medida em que apresentam certa visão de mundo (AMOSSY, 2005).

Com essa hipótese, Amossy (2005) defende um alargamento do campo de abrangência da retórica, que, aliada à Análise do Discurso, não precisaria se restringir ao estudo de corpora onde há a presença explícita de uma dissensão, bem como a 
existência declarada de um proponente e de um oponente. Isso não significa, contudo, que não é necessário o conflito; apenas exclui-se a obrigatoriedade do conflito declarado.

Se admitirmos a distinção entre dimensão e visée argumentativas, de acordo com a autora, podemos estender a análise argumentativa a corpora tradicionalmente olvidados pela retórica, para submetê-los a uma avaliação em termos de interação e de eficácia. Abre-se também a possibilidade de pensar que existem meios de agir sobre o outro que não são reportados nos catálogos de técnicas argumentativas. Como afirma Amossy:

\begin{abstract}
[Os discursos] tanto utilizam a seu modo as técnicas argumentativas descritas nos tratados de argumentação e nos manuais de retórica - como o entimema, a analogia, a definição, as figuras de estilo etc. - como empregam meios particulares encontrados nos recursos da língua, da arte da narrativa ou do estilo - como o parenthèse, o discurso reportado, o encaixe de vozes narrativas, o ritmo, a escritura branca, etc. Aos tipos de argumentos e às figuras retóricas se juntam assim numerosos e diversificados meios verbais. (AMOSSY, 2005, p. 167, tradução nossa) ${ }^{1}$.
\end{abstract}

A análise argumentativa resultante desse amálgama entre retórica e Análise do Discurso também não imporia restrições à utilização dos instrumentos fornecidos pela Teoria da Argumentação na Língua, de Ducrot (1989), no que se refere, sobretudo, aos elementos que garantem a ligação entre enunciados e que conferem a eles sua dimensão argumentativa, a saber, os conectores e os topoï pragmáticos (AMOSSY, 2005).

Amossy (2002) postula que a obra de Perelman já se encontra bastante adaptada aos recursos da linguística do discurso nas suas vertentes enunciativa e pragmática, no que se refere à atenção dada à situação de enunciação, à função do alocutário, ao saber comum e aos pressupostos que autorizam a interação verbal, assim como à eficácia da palavra definida em termos de ação. Identifica, assim, na obra de Perelman, a presença da concepção do quadro enunciativo de Benveniste (1989), ao apresentar e desenvolver sua Nova Retórica não como sistema à maneira estruturalista, mas como uma situação de troca entre parceiros no discurso, que visa, em última instância, à ação de um sobre o outro, pela palavra.

Para a autora, a retórica, da qual se alimenta Perelman, e também a linguística da enunciação, analisam a linguagem "em situação", na sua dimensão intersubjetiva, em que o eu implica um tu, mesmo quando este não esteja explicitado por marcas linguísticas. Em suma, na perspectiva retórica adotada pela Nova Retórica, todo enunciado é necessariamente direcionado no sentido do alocutário, com vistas a orientálo nos modos de ver e de pensar. O sujeito falante aciona o aparelho formal da enunciação não só para se comunicar, mas também para agir sobre o indivíduo a quem se dirige.

\footnotetext{
${ }^{1}$ Tantôt ils utilisent à leur façon les techniques argumentatives décrites dans les traités d'argumentation et les manuels de rhétorique - comme l'enthymème, l'analogie, la définition, les figures de style, etc. Tantôt ils emploient des moyens particuliers puisés dans les ressources de la langue, de l'art du récit ou du style - comme la parenthèse, le discours rapporté, l'emboîtement des voix narratives, le rythme, l'écriture blanche, etc. Aux types d'arguments et aux figures rhétoriques se joignent ainsi des moyens verbaux nombreux et diversifiés.
} 
Outro ponto observado por Amossy (2002) é o de que, no Tratado da argumentação, Perelman e Olbrechts-Tyteca (1996) afirmam que todo o processo argumentativo, desde a escolha das premissas até as palavras empregadas pelo orador no seu projeto de persuasão, é sujeito à incidência de valores, tanto que a argumentação, para eles, é uma lógica dos juízos de valor. Perelman e Olbrechts-Tyteca (1996) também se referem, no Tratado, à escolha da qualificação e à apresentação dos dados do discurso. Eles mostram que, na seleção de epítetos e de qualificações para um determinado objeto, há uma clara orientação argumentativa. Assim, chamar a Revolução Francesa de "sangrenta revolução" revela claramente um propósito e uma direção argumentativa.

Essa incidência dos valores e, consequentemente, da subjetividade na língua, é estudada de forma mais pontual pela linguística, através da pesquisa dos procedimentos linguísticos (shifters, modalizadores, termos avaliativos, etc.) pelos quais o locutor imprime sua marca à enunciação, se inscreve na mensagem e se situa em relação ao outro. Essa marca pode ser encontrada pela análise linguística dos substantivos axiológicos (positivos ou negativos), dos adjetivos afetivos (aqueles que enunciam, ao mesmo tempo, uma propriedade do objeto que eles determinam e uma reação emocional do sujeito falante diante desse objeto), dos verbos ocasional ou intrinsecamente subjetivos (AMOSSY, 2002).

Outra questão que perpassa o trabalho de linguistas e neorretoricistas é o reconhecimento do papel constitutivo do alocutário. Um dos postulados centrais da Nova Retórica é a necessidade de adaptação do orador a seu auditório. Amossy (2002) reconhece que, sob uma mesma perspectiva, Nova Retórica e Ciências da Linguagem se interrogam sobre as modalidades de inscrição do alocutário no discurso. Embora não faça menção expressa a Bakhtin (1997), essa preocupação de Perelman com o auditório mostraria, conforme a autora citada, os influxos do dialogismo em sua obra.

Perelman (1987) observa que o tipo de auditório visado determina quais as melhores técnicas argumentativas a serem empregadas pelo orador. Em função de suas características, os auditórios podem ser classificados como particular ou universal, homogêneo ou heterogêneo, simples ou compósito. As Ciências da Linguagem, segundo Amossy (2002), preocupam-se menos com a natureza do auditório e mais com os modos de presença do alocutário na comunicação, de forma que estabelecem classificações quanto às instâncias de recepção em função do grau de presença e de atividade, em trabalhos desenvolvidos sobretudo por Goffman (1967).

$\mathrm{Na}$ teoria da argumentação perelmaniana, o discurso se apoia sobre as crenças e as opiniões em voga no meio social: para começar a desenvolver uma argumentação, o orador deve estabelecer antes um acordo com o auditório, sendo que para Perelman (1987), esse acordo repousa sobre os fatos (aquilo que é considerado como tal), as verdades (aquilo que o público entende como verdade) e as presunções (que se cuidam válidas em função das normas admitidas). A partir dessas bases, o orador pode prosseguir em seu discurso argumentativo, apoiando-se em técnicas de ligação e de dissociação, em função dos esquemas lógico-discursivos que desfrutam de largo reconhecimento, até a generalização. Perelman (1987) se apropriaria assim dos lugares 
comuns de Aristóteles, ou topoï, com pequenas alterações, e insistiria no papel persuasivo dos lugares do preferível (valores, hierarquias e lugares).

Amossy (2002) explicita que essa abordagem dos topoï busca determinar os grandes esquemas lógico-discursivos que articulam e modelam os raciocínios, mostrando que sua força de convicção depende, em parte, dos lugares comuns sobre os quais eles se edificam. A Pragmática, que se interessa igualmente pelas premissas e pelos tópicos implícitos sobre os quais se fundam os enunciados ou os encadeamentos de enunciados, busca também reencontrá-los na materialidade linguística.

Enfim, ao fundamentar a arte da persuasão no bom uso dos tópicos, Perelman, na visão de Amossy (2002), adianta os trabalhos da linguística contemporânea, especialmente da Semântica e da Pragmática que, sob ângulos diversos, estudam a pressuposição, as implicações e os topoï que asseguram o encadeamento dos enunciados e seu impacto na interação.

Nessa perspectiva, os trabalhos de Perelman evidenciam a importância dos fundamentos do discurso argumentativo, a saber: dos tópicos, da doxa, do conhecimento partilhado do senso comum, no qual o locutor se fundamenta para construir desde as premissas iniciais até a conclusão, tudo isso discursivamente orientado para a persuasão de um auditório.

Todos esses fundamentos são utilizados por Amossy (2006) em sua proposta de análise da argumentação no discurso, o que evidencia também a influência profunda de Aristóteles (1998) na formação de seu quadro teórico. Observa-se ainda essa influência na retomada que a autora faz dos gêneros retóricos, para desenvolvê-los então à luz do dialogismo de Bakhtin (1997).

Para Amossy (2006), tanto a retórica como a Análise do Discurso colocam o gênero em posição capital. Contudo, ao analisar a obra de Perelman, Amossy (2006) aponta que os discursos literário, filosófico, político e jurídico são abordados como extratos, fragmentos extraídos aleatoriamente de um substrato maior, ao qual parecem não dever sua própria essência. Nesse sentido, afirma-se que Perelman não explora as modalidades argumentativas próprias aos diferentes gêneros do discurso. Os esquemas de pensamento que sustentam a argumentação, bem como os procedimentos de ligação e ruptura que podem ser mobilizados nas situações mais diferentes, seriam por ele analisados sem se levar em conta a variação de um regime discursivo a outro (AMOSSY, 2005).

Nesse aspecto, em sua proposta de análise argumentativa, a autora recebe os influxos de Bakhtin (1997) e da tradição de estudo dos gêneros discursivos, segundo a qual cada gênero adota as modalidades de persuasão verbal que the são mais convenientes. Assim, considera que a argumentação se encontra em uma relação de dependência com o domínio do qual ela emerge e com gênero no qual se insere:

\footnotetext{
Não tentamos influenciar um júri no curso de um processo como tentamos fazer eleger um candidato em uma campanha eleitoral, ou fazer partilhar nossas opiniões por um amigo em uma conversação familiar, ou suscitar a reflexão do leitor sobre um estado do mundo em um texto romanesco. (AMOSSY, 2005, p. 167)
} 
Para Amossy (2005), as estratégias argumentativas relacionadas ao logos, ao ethos e ao pathos são em boa parte modeladas pelo gênero de discurso. Por exemplo, no que diz respeito ao $\log o s$, a autora entende que o grau de formalização do raciocínio, assim como a escolha e o agenciamento dos argumentos, diverge manifestamente de um quadro a outro, mesmo se as teses defendidas pelo locutor forem similares.

Em relação ao pathos, a autora postula que o quadro genérico dita as modalidades de apelo às emoções, sua intensidade e até a sua legitimidade (em uma carta de amor, por exemplo, é comum um tom fortemente afetivo por parte do locutor, ao contrário de um artigo científico, tradicionalmente pouco afeito às emoções).

Quanto ao ethos, Amossy (2005) defende que cada gênero compreende uma distribuição prévia dos papéis que modelam o dispositivo de enunciação, para o qual não se pode negar a importância do estatuto do locutor e do quadro institucional no qual ele profere sua palavra. A eficácia da palavra depende também da posição daquele que a detém e do grau de legitimação que ele desfruta no seu meio social. A legitimidade do locutor, sua posição social e institucional e sua reputação desempenham, na visão da autora, importante papel na troca argumentativa.

\section{CONSIDERAÇÕES FINAIS}

Neste trabalho, apresentamos uma retrospectiva dos estudos sobre argumentação de procedência retórica. Dessa forma, iniciamos nossa reflexão discorrendo sobre a retórica e sua conformação na Grécia Antiga. Em seguida, passamos por Perelman e seu engenhoso trabalho de revitalização dos postulados retóricos e, por último, abordamos as pesquisas de Ruth Amossy, considerada a maior legatária, na atualidade, de toda essa tradição filosófica.

Pontuamos que, no domínio da retórica, a argumentação é construída a partir do que é verossímil: premissas verossímeis relacionadas entre si permitem que se chegue a uma conclusão também verossímil. O critério de verossimilhança é subjetivo, de forma que seu preenchimento demanda a avaliação da qualidade das premissas pelo público almejado. A partir desse critério, adquire relevo a importância do auditório para o sucesso de um projeto argumentativo.

Essa questão da importância da adequação do orador a seu auditório é notadamente desenvolvida por Perelman (1987). Sob o influxo da retórica aristotélica, o autor elabora sua teoria enfatizando que a argumentação se realiza em função de um ou mais alocutários, que têm o poder de decidir sobre o que é aceitável ou não. Para esse autor, o bom andamento de uma argumentação está atrelado, portanto, à opinião do outro. Por isso, é preciso que o locutor disponha de premissas fortes e que saiba gerenciar técnicas linguageiras que lhe possibilitem alcançar a razão e os sentimentos de seu público, o que se traduz pelo conceito de persuasão. Para essa finalidade, os oradores administram um repertório de estratégias mais ou menos racionais, sem prescindir do elemento emocional. Mesmo nesse espaço flexível, existem princípios e regras a serem observados e qualquer forma de violação implica a desqualificação do orador e até mesmo da própria argumentação. 
Amossy (2006), em sua teoria da argumentação no discurso, recebe também a influência da retórica aristotélica. Ao retomar os estudos desenvolvidos por Perelman (1987) em torno da adaptação do orador ao auditório e das técnicas argumentativas utilizadas para se obter a persuasão, a pesquisadora busca conciliar todo esse arcabouço de base filosófica a uma visão linguística e discursiva da argumentação, de forma a possibilitar uma abordagem de corpora de visée persuasiva no âmbito das Ciências da Linguagem. Nesse sentido, consideramos que a articulação empreendida por Amossy entre os postulados filosóficos da retórica aristotélica, os constructos da Nova Retórica de Perelman (1987) e as contribuições da Análise do Discurso constitui um avanço notável no campo dos estudos da argumentação, sobretudo no que diz respeito à investigação do quadro institucional que modela e determina o funcionamento discursivo voltado à persuasão; a análise dos gêneros discursivos e sua influência sobre a escolha das estratégias argumentativas; o estudo do papel do ethos e das emoções para a persuasão, entre outros aspectos.

Em suma, defendemos que com essa articulação entre retórica, Nova Retórica e Análise do Discurso, Amossy (2006) fornece ao pesquisador um referencial teóricometodológico que permite a realização de uma ampla análise linguístico-discursiva de diversos corpora de natureza persuasiva, pertencentes aos mais diferentes domínios, como o jurídico, o político e o midiático, sem perder de vista seu conteúdo filosófico.

\section{REFERÊNCIAS}

AMOSSY, R. Nouvelle rhétorique et linguistique du discours. In: KOREN, R. ; AMOSSY, R. (Orgs.) Après Perelman: quelles politiques pour les nouvelles rhétoriques? Paris: L'Harmattan, 2002. p. 153-171. Rhétorique et analyse du discours. Pour une approche socio-discursive des textes. In : ADAM, J. M. ; HEIDMANN, U. (Orgs.). Sciences du texte et analyse de discours. Etudes de Lettres, 2005. L'argumentation dans le discours. Paris: Armand Colin, 2006.

ARISTÓTELES. Retórica. Lisboa: Imprensa Nacional - Casa da Moeda, 1998.

Tópicos. Disponível em <http://www.dominiopublico.gov.br/download/texto/cv000069.pdf>. Acesso em: 02 fev. 2011.

AUSTIN, J. L. Quando dizer é fazer: palavras e ações. Porto Alegre: Artes Médicas, 1990.

BAKHTIN, M. Estética da criação verbal. Tradução de Maria Ermantina Galvão Pereira. São Paulo: Martins Fontes, 1997.

BENVENISTE, É. O aparelho formal da enunciação. In: Problemas de Lingüística Geral II. Tradução de João Wanderlei Geraldi. Campinas: Pontes, 1989. p. 81-90.

CHARAUDEAU, P. Linguagem e discurso: modos de organização. São Paulo: Contexto, 2009.

DASCAL, M. Interpretação e compreensão. São Leopoldo: Unisinos, 2006.

DUCROT, O. Argumentação e “topoi” argumentativos. In: GUIMARÃES, E. (Org.) História e sentido na linguagem. Campinas: Pontes, 1989. p.13-38.

EEMEREM, F. van; HOUTLOSSER, P. Une vue synoptique de l'approche pragma- dialetique. In: DOURY, M.; MOIRAND, S. (Eds.). L' argumentation aujourd'hui. Positions théoriques en confrontation. Paris: Presses Sorbonne Nouvelle, 2004. p. 103-124.

GOFFMAN, E. Interaction ritual: essay on face-to-face behavior. Nova York: Anchor Books, 1967. HABERMAS, J. Pensamento pós-metafísico: estudos filosóficos. Rio de Janeiro: Tempo Brasileiro, 1990. 
MENEZES, W. A. Evento, jogo e virtude nas eleições para a presidência do Brasil - 1994 e 1998. 2004. 484f. Tese (Doutorado em Linguística) - Programa de Pós-graduação em Estudos Linguísticos, Faculdade de Letras da Universidade Federal de Minas Gerais, Belo Horizonte, 2004.

MOSCA, L. do L. S. Velhas e Novas Retóricas: convergências e desdobramentos. In: MOSCA, L. do S. (Org.). Retóricas de ontem e de hoje. 2. ed. São Paulo: Humanitas Editora/ FFLCH/ USP, 2001. p. 17-54. PERELMAN, C. Argumentação. Enciclopédia Einaudi. v. 11. Lisboa: Imprensa Nacional-Casa da Moeda, 1987. p. 234-265.

PERELMAN, C.; OLBRECHTS-TYTECA, L. Tratado da argumentação: a Nova Retórica. Tradução de Maria Ermantina Galvão. São Paulo: Martins Fontes, 1996.

PLANTIN, C. Analyse et critique du discours argumentatif. In: KOREN, R.; AMOSSY, R. (Orgs.) Après Perelman: quelles politiques pour les nouvelles rhétoriques? Paris: L'Harmattan, 2002. p. 229-263.

REBOUL, O. Introdução à Retórica. Tradução de Ivone Castilho Benedetti. São Paulo: Martins Fontes, 2004.

\section{Recebido em: 28/08/13. Aprovado em: 12/07/14.}

Title: Rhetoric, argumentation and discourse under perspective

Author: Maysa de Pádua Teixeira Paulinelli

Abstract: In this paper, we propose a retrospective study of rhetorical argumentation theories. We aim the reconstruction of the critical paths followed since the classical world, to contemporary research in the field of discourse analysis. We initially discuss classical rhetoric and then we present the principles of the New Rhetoric, by Chaï Perelman, and argumentation in discourse, by Ruth Amossy. After identifying and correlating the main aspects of each theoretical basis, we concluded that the New Rhetoric is a philosophical model whose categories have practical difficulties of operation, due to its high degree of abstraction. Thus, to articulate the philosophical assumptions of Perelman and the contributions of discourse analysis, Amossy promotes a remarkable advance in argumentation studies, providing the researcher with a theoretical and methodological framework that enables the realization of a linguistic-discursive analysis of various persuasive corpora.

Keywords: Rhetoric. Persuasion. Argumentation. Discourse.

Título: Retórica, argumentación y discurso en retrospectiva

Autor: Maysa de Pádua Teixeira Paulinelli

Resumen: En este trabajo, proponemos la elaboración de una retrospectiva de estudios da argumentación de origen retórico, con vistas a reconstrucción crítica de las rutas desde el mundo clásico hasta investigaciones más contemporáneas en ámbito del Análisis del Discurso. Descorrimos inicialmente sobre la retórica clásica, y luego presentamos los postulados de la Nueva Retórica de Chaïm Perelman, y de la argumentación en el discurso de Ruth Amossy. Después de identificar y de hacer correlación con los principales aspectos de cada cuerpo teórico, concluimos que la Nueva Retórica es un modelo filosófico cuyas categorías presentan dificultades prácticas para hacer las operaciones necesarias, debido su alto grado de abstracción. De esa manera, cuándo articula los postulados filosóficos de Perelman y las contribuciones del Análisis del Discurso, Amossy promueve un avanzo notable en el campo de estudios de la argumentación, proveyendo al investigador un referencial teórico y metodológico que permite la realización de un amplio análisis lingüistico-discursivo de diversos corpora de naturaleza persuasiva.

Palabras-clave: Retórica. Persuasión. Argumentación. Discurso. 